University of Nebraska - Lincoln

DigitalCommons@University of Nebraska - Lincoln

Nancy Shank Publications

Public Policy Center, University of Nebraska

$1-2011$

\title{
Faith-Based Organizations in a System of Behavioral Health Care
}

\author{
Mark DeKraai \\ University of Nebraska Public Policy Center, mdekraai2@unl.edu \\ Denise Bulling \\ University of Nebraska Public Policy Center, dbulling2@unl.edu \\ Nancy C. Shank \\ University of Nebraska Public Policy Center, nshank@nebraska.edu \\ Alan J. Tomkins \\ University of Nebraska Public Policy Center, atomkins@nebraska.edu
}

Follow this and additional works at: https://digitalcommons.unl.edu/publicpolicyshank

Part of the Public Policy Commons

DeKraai, Mark; Bulling, Denise; Shank, Nancy C.; and Tomkins, Alan J., "Faith-Based Organizations in a System of Behavioral Health Care" (2011). Nancy Shank Publications. 5.

https://digitalcommons.unl.edu/publicpolicyshank/5

This Article is brought to you for free and open access by the Public Policy Center, University of Nebraska at DigitalCommons@University of Nebraska - Lincoln. It has been accepted for inclusion in Nancy Shank Publications by an authorized administrator of DigitalCommons@University of Nebraska - Lincoln. 


\title{
FaIth-BASED ORganizations in A System of Behavioral Health Care
}

\author{
Mark B. DeKraai, Denise J. Bulling, \\ NANCY C. SHANK, and Alan J. TOMKINS \\ University of Nebraska
}

Through community service activities, and ministries to members within their congregations, faith communities will encounter individuals with behavioral health needs. This article suggests that faith communities have inherent resources that can enhance the reach and effectiveness of behavioral health systems. A framework is presented that will create a bridge of understanding about how behavioral health can leverage faith organization assets and how faith organizations can actively assist adults, children and families with behavioral health needs within the context of their faith and their community.

$\mathrm{T}$ Throughout the history of the United States, faith communities have delivered community services. Guided by theology, faith communities pioneered the provision of care for populations such as orphans, unmarried mothers, the elderly, persons with disabilities, and persons who were ill, homeless, or lacked resources. As government entities, not-for-profits, and for-profit organizations have taken a more dominant role in funding and delivering health and human services, faith communities have continued to play an active, though less obvious, role in providing community services. At least one in five congregations report supporting

The authors are all members of the University of Nebraska Public Policy Center and coordinated one of the first Bush Administration's faith-based grants, Community-Based and Faith-Based Organizations: Partners in an Integrated System of Behavioral Health Care in Nebraska (90EJ0010), Office of Community Services, US HHS. We appreciate the research assistance on this manuscript provided by graduate students in the UNL Department of Sociology, Jill Thayer and Yolanda Dillion; the vast assistance on many levels, research and otherwise, provided by Kim Loontjer and Carmen McLean, and the many contributions of Caroline Walles, who taught us not only nuanced understanding of faith communities but also exemplified the connectivity of the faith and behavioral health fields. The authors may be contacted at the University of Nebraska Public Policy Center, 215 Centennial Mall South, Suite 401. PO Box 880228, Lincoln, NE 68588-0228 (http://ppc.nebraska.edu/). or providing cash assistance, food assistance, hospi$\mathrm{tal} /$ nursing facilities, counseling/hotlines, elderly housing and other senior services, services in prison, child care, substance abuse services, tutoring, health education, or employment services (Dudley \& Rozen, 2001); hence, faith communities continue to play a vital role in community services that create a "national, personal network of human services extending to virtually every community" (Dudley \& Rozen, p. 46; see also Canning, 2005). The pervasiveness of community services among faith communities is particularly striking given that many congregations lack adequate physical facilities, only a small minority enjoy excellent financial health, and half have fewer than 100 people participate on a regular basis.

The faith community and behavioral health communities have a long tradition of working together to address the needs of persons with mental illness and substance abuse disorders (e.g., Kloos, Horneffer, \& Moore, 1995; Kress \& Elias, 2000; Maton \& Pargament, 1987; McRay, 2001; Spriggs \& Sloter, 2003), albeit in non-systematic ways and often not effectively. Although the Federal Faith-Based Initiative was controversial, it has continued through the Bush Administration and into the Obama Administration (e.g., Kramer, 2010). Consequently, it seems the right time to consider models that support effective partnering among faith communities and behavioral health systems. In this article, we provide a model for how congregations and their ministries can become part of the behavioral health services solution. ${ }^{1}$ This model provides guidance for behavioral health systems about how to more effectively use and understand the assets of faith communities and suggests ways ministries can use their strengths to take an active role in meeting behavioral healthcare

${ }^{1}$ This article does not address treatment models that incorporate spirituality or religion as part of a treatment approach (see, e.g., Richards \& Bergin, 2000). 
needs of people in their community. The roots of this model are in Bronfenbrenner's (1979) ecological model of intersecting systems that are best understood in a dynamic network that have an inherent hierarchal order. The model is based on two premises: 1) the inclusion of faith-based organizations in the behavioral health system of care is critical for an effective response to mental health and substance abuse disorders, and 2) faith communities can provide a variety of effective service options to fill needed gaps in the system of care.

\section{The Importance of THE FAITH Community in a BeHAVIORAL Health System of Care}

\section{Challenges Confronting the Behavioral Health System}

Collectively, behavioral health disorders ${ }^{2}$ are the most prevalent health problem in America today more common than cancer, lung disease and heart disease combined (see, e.g., National Council for Community Behavioral Healthcare, n.d.). Over 20\% of adults annually experience a diagnosable mental disorder (e.g., National Institute of Mental Health, 2003). Approximately 22 million Americans are dependent upon or abuse drugs or alcohol (Substance Abuse and Mental Health Services Administration, 2003). Stigma surrounding the receipt of mental health treatment is among the many barriers that discourage people from seeking treatment (e.g., New Freedom Commission on Mental Health, 2003). Nearly two-thirds of all people with diagnosable mental disorders do not seek treatment (e.g., U.S. Department of Health and Human Services, 1999a).

Untreated behavioral health disorders contribute to lost productivity, unemployment, homelessness, increased school drop-out rates, higher suicide rates, and overcrowded jails and prisons. Effective behavioral health service provision is undermined by gaps in services, absence of information about where to seek services, long waiting lists, and factors such as culture and language barriers that restrict service accessibility. The President's New Freedom Commission on Mental Health (2003) reports that rural communities, minority groups, persons with dual diagnoses of mental illness and substance abuse, the elderly, and youth transitioning from child-serving systems to adult ser-

\footnotetext{
${ }^{2}$ Behavioral health as discussed herein includes mental health, substance abuse and other addictions such as gambling.
}

vices are particularly underserved in the U.S.

The New Freedom Commission on Mental Health (2003) also identified a number of shortcomings of the current system: disparity in insurance benefits for behavioral health care as compared to physical healthcare, the lack of coordination among components of the system, the complexity of the system, the absence of early identification and intervention, and the scarcity of an adequately trained work force. Although system reforms can improve the response to behavioral health disorders, they are unlikely to form a complete solution.

Increasingly, behavioral health scholars have recognized the need to involve multiple partners in addressing needs of persons with behavioral health disorders. People with behavioral health problems have unique challenges in meeting their basic needs such as food, shelter, employment, education, spirituality, social needs, recreation, and so on. Only through partnerships that include behavioral health, faith organizations, and community institutions along with consumers and their families, can the inadequacies of the current system be addressed and individual needs met. Although there is substantial literature (e.g., Stroul, 1996) defining partnerships among behavioral health providers, consumers, and community delivery system (e.g., education, welfare, criminal justice), there is little discussion regarding the role of faith organizations within a system of care. Yet, congregations, community ministries, parish social ministries and other faith groups are in a unique position to address some of the most critical problems in the behavioral health system (e.g., Ali, Milstein, \& Marzuk, 2005; Clemens, 2005; Dossett, Fuentes, Klap, \& Wells, 2005). Unfortunately, many faith organizations are not aware of their important role in a system of care.

\section{Assets of the Faith Community}

Behavioral health disorders are a significant challenge for our society. To address this challenge requires a comprehensive, coordinated response from multiple partners. Given the assets and untapped potential of faith based organizations, it is important that they be included along with secular service providers, public and private funding agencies, support systems, and consumers of behavioral health services in crafting an effective behavioral health service delivery system (see Figure 1).

Faith-based organizations may play an important role in social change designed to improve the 
Figure 1: Integrated behavioral health system that includes faith organizations.

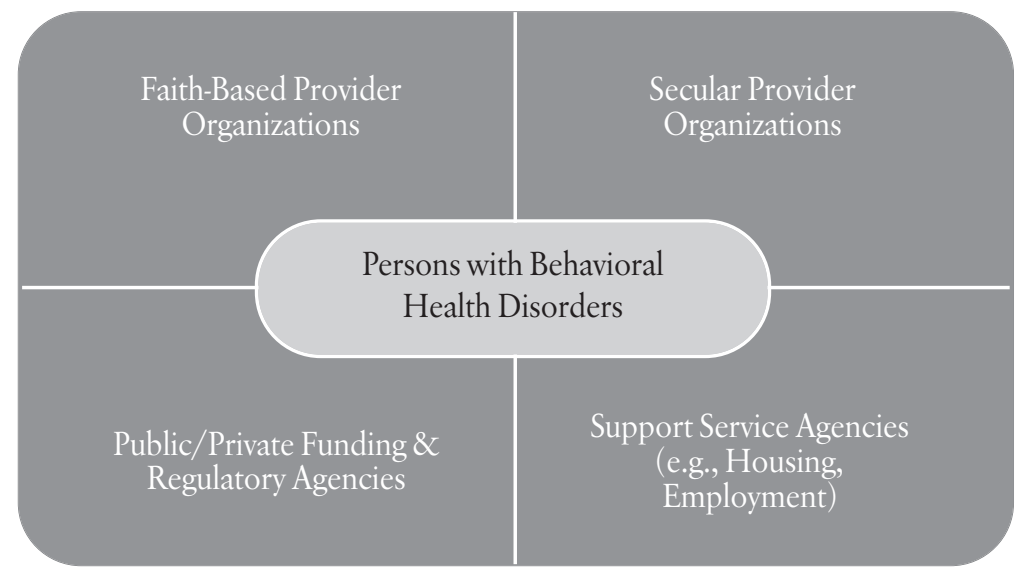

behavioral health of individuals. Individuals live, work and play within social support networks, neighborhoods, communities. The nature and quality of the social environment contributes to the overall behavioral health of individuals. In addition, the availability and quality of behavioral health interventions for individuals is a public policy issue, subject to influence by community initiatives and organizations. Faith-based organizations may participate in public education and advocacy in an effort to achieve objectives such as reducing the stigma of mental illness and substance abuse or influencing public officials in developing community, state or national policies related to behavioral health (e.g., Small, 2001, 2002).

Faith-based organizations can be instrumental in the development of coalitions (e.g., Christens, Jones \& Speer, 2008; Speer, Peterson, Zippay, \& Christens, 2010). Coalitions can be more effective in bringing about social change or creating a community initiative than a single organization by itself. Generally, coalition building involves distinct stages: bringing people together around a common cause, building trust among the participants, developing a vision and strategic plan, maximizing community resources to implement the plan, and expanding the initiative (Thompson, 1993). By partnering with other religious and secular groups, faith-based organizations are capable of mobilizing individuals and groups to form community partnerships and can offer a variety of assets to the partnership such as meeting space, physical resources for copying or mailing, and human resources (Kretzmann \& McKnight, 1993). Faith organizations are often a strong element of the local community, and may be perceived more positively and with less skepticism and suspicion than service agencies.

Less visible, but longstanding, is the role that faith leaders assume when providing counsel to people with emotional problems (Foskett, 2001). Studies suggest that churches provide a wide range of services such as substance abuse assistance, health screenings, education and support (e.g., Caldwell, Greene, \& Billingsley, 1994; Drayton-Brooks \& White, 2004). Faith-based institutions are especially valuable as partners in the attempt to link formal and informal systems of care for the benefit of underserved or disenfranchised populations (e.g., Caldwell et al., 1994; Eng, Hatch, \& Callan, 1985; Hatch \& Derthick, 1992; Taylor, 1986; Taylor \& Chatters, 1986a, 1986b).

Communities of faith are important gateways to professional behavioral health treatment. Wang and his colleagues (2003) noted that the number of individuals turning to clergy when experiencing emotional problems fell in the 1960's and 1970's, stabilized in the 1980's and rose in the 1990's. They estimated that $25 \%$ of persons requesting behavioral health assistance for the first time initially sought it from clergy. The physical proximity of religious groups to underserved populations and the trust placed in the institution creates unique opportunities for faith-based groups to serve as a resource (e.g., Allard, Tolman, \& Rosen, 2002; Brat, 2001; 
Voss, 1996). Religious institutions in communities routinely touch the lives of people with behavioral health needs, many of whom have had difficulty accessing behavioral health care for a variety of reasons. The congregation is the place where "the stranger is welcomed" and the poor are given food and shelter. Gunderson (1997) characterizes congregations as bringing people together by convening, connecting, and providing opportunities for building relationships.

Faith groups interested in addressing society's behavioral health issues may benefit from a model that describes service delivery in terms that have relevance to traditional roles religious groups have assumed in social service provision. A model would enable congregations, faith-based organizations, and community ministry groups to match their strengths, or callings, to a service that can effectively support people with behavioral health problems in the context of the larger behavioral health system of care.

Existing models of outreach embraced by many faith communities include the Parish Nurse Model, Community Ministry, and Lay Counseling. The Parish Nurse model promotes wellness and healing in congregations by integrating community nursing functions with faith community activities (Miskelly, 1995). This approach depends on the presence of an "expert" who can teach and organize volunteers to assist in health and wellness awareness and prevention efforts. The Community Ministry movement is a grassroots social ministry that involves work done to better a community by a cluster of congregations, often of different denominations or faith (Bos, 1993). Community Ministry may involve outreach, advocacy, direct service, social justice, or other types of programs, projects or services to meet community needs or fill gaps. Bos (1993) identified seven benefits to congregations who engage in community ministry: (1) It enables congregations to relate to a total community; (2) It encourages a sense of pastoral responsibility for the immediate neighborhood; (3) It furthers indigenous cultural, social and other patterns important to the identity of the area; (4) Church members have a sense of both giving and receiving through active volunteering; (5) It expands the concept of congregation to include the way it relates to the community at large; (6) It increases the respect of the congregation for the neighborhood as a gift from God; and (7) It provides a concrete means by which the congregation can express its faith.
Another model is lay counseling in which nonprofessionals assist others with personal problems including the stresses of life (See Atkins \& Christensen, 2001; Christensen \& Jacobson, 1994; Tan, 1991, 2002). Lay counselors generally have limited professional training, but are motivated to care for other people. Lay counseling can occur within congregations or as outreach to prisoners, to persons who are homeless, or to others in need. This efforts builds on the community psychology and social work framework promoting the use of non-professionals as helpers and connectors to services for people in need (e.g., Bergman, 1974; Bissonette, 1977a, 1977b; Brown, 1974; Collins, 1973; Cowen, 1982; D’Augelli \& Vallance, 1981; Gordon, 1974, Hunter \& Riger, 1986; Johnsson \& Berglund, 2003; Kelley \& Kelley, 1985; McKim \& Weissberg, 1981; Morton \& Joseph, 1971; Roach \& Resnick, 1981; Zarle, Hartsough, \& Ottinger, 1974).

Other ministries in faith communities may also be built upon to include specific behavioral health focused efforts. For example, Social Justice Ministries attempt to address the root causes of poverty and social problems and Health Ministries promote wellness through outreach and education efforts. In the next section, we build on these ministry models to propose a specific framework for faith communities to focus on behavioral health.

\section{SERVICE OPTIONS FOR FAITH ORganizations}

The faith-based behavioral health model is graphically represented by a pyramid. The service pyramid is divided into three broad areas of behavioral health care-clinical care, support services, and informational services (see Figure 2). Each area is presented with an explanation of activities commonly associated with that service in behavioral health systems of care.

\section{Treatment/Clinical Care- The Tip of the Pyramid}

Treatment and clinical care represents the tip of the behavioral health pyramid. These are ministry opportunities where the fewest faith communities will be prepared to participate because they are the most intensive and involved. Laws, state and federal regulations, and national accreditation standards determine the licensure or certification needed for professionals to provide clinical behavioral health treatment at all levels of clinical care. Clinical care 
Figure 2. The Role of Faith-Based/Community Organizations in a System of Care.

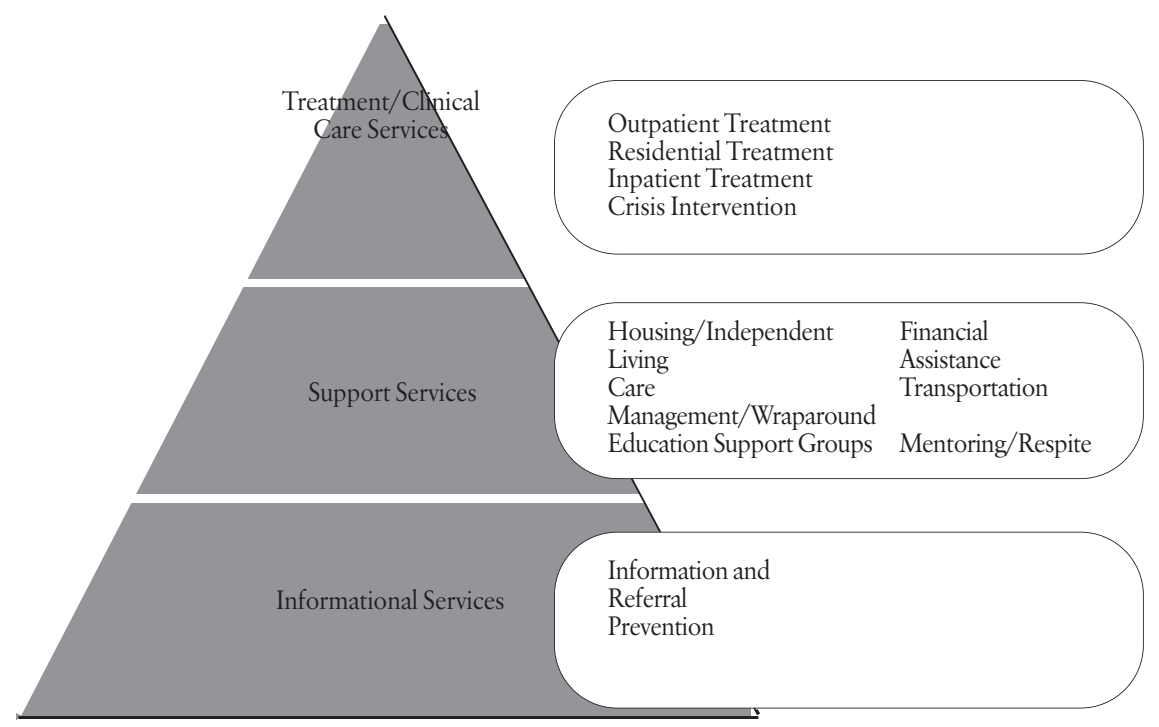

can be delivered in environments like the home or office (outpatient settings), a halfway house or 24hour facility (residential settings), or hospitals (inpatient setting), or in the community through crisis intervention services. Each of these services is reviewed below.

Outpatient Service. Mild to moderate problems are often treated in an office, the recipient's home, or other location that is community-based and private. These are referred to as outpatient services and can include interventions with an individual, group of consumers, or a family. Outpatient services range in intensity and format. They can vary from 15 minutes with a medical professional to a series of interventions delivered in several hours as part of a partial hospitalization or day treatment program. Lutheran Family Services of America, Samaritan Counseling Centers, and Catholic Social Services are examples of large organizations associated with denominations or faith groups that deliver outpatient mental health and substance abuse services that meet licensure and accreditation standards. Smaller faith-based groups in all parts of the country have also set up outpatient clinics or services with either paid or volunteer professionals as providers of care.

Residential Treatment. Some people with moderate or severe problems are treated and live in resi- dential facilities. The environment is structured, and features 24 hour monitoring as well as participation in clinical treatment. A person in residential treatment also receives help in the development of skills needed for daily living or management of an illness like alcoholism or schizophrenia. The intensity of service in residential treatment is often higher than that of clinical outpatient services alone. The residential treatment setting includes interventions delivered by licensed or certified professionals and 24 hour monitoring by persons trained in mental health or addiction recovery. Halfway houses or transitional living facilities are examples of residential treatment. Residential treatment helps people in transition from institutions to the community or may be an alternative to hospitalization for people with moderate mental health or substance abuse problems. For children with serious emotional disorders, treatment foster care is home-like residential service for specially trained treatment foster parents (see, e.g., Chamberlain, 2002; Chamberlain \& Moore, 1998).

Hospitalization or Inpatient Service. Persons with severe behavioral health problems may need hospitalization or inpatient services. A person in this level of care is required to stay at the facility where they are monitored and treated by medical professionals 24 hours a day. Often, the need to 
protect the public or the individual may prompt an admission to this level of care. The difference between hospitalization and residential treatment is in the severity of problem being treated, the intensity of the service and the type of professional needed to provide treatment. Service at the inpatient level of care, in a hospital setting, is the most restrictive and the most expensive. This level of care is offered in accredited facilities (hospitals) that can be affiliated with specific denominations or faith groups. The hospital is seldom seen as a ministry of a specific congregation. It is more likely a business extension of a large faith group that includes opportunities for ministry.

Crisis Intervention Service. People with mild, moderate, or severe symptoms of a behavioral health problem may access care through a Crisis Intervention Service. This service includes active intervention aimed at assessing the level of severity of a problem or complaint, stabilizing the individual, and safely returning them to a higher level of functioning. Crisis Intervention services include hot lines, mobile intervention teams, emergency assessment, and pastoral intervention. Crisis services can range from the heavily professional mobile emergency teams to a hotline staffed entirely by volunteers. The Rural Response Hotline in Nebraska operated by Interchurch Ministries of Nebraska is an example of a faith-based organization offering crisis services. The hotline is staffed by professionals and trained volunteers who assess and intervene with people in crisis in rural Nebraska. Needs of the caller are assessed, interventions are offered and the caller is referred to the appropriate level of care if appropriate. Vouchers for use with mental health and substance abuse outpatient care are available for callers through the line. Volunteers involved in this type of service are usually expected to train extensively and operate under supervision of a professional.

Pastoral crisis intervention is normally seen as an expected part of the faith leader's ministry to others. It has been described as the functional integration of pastoral activities with traditional crisis intervention/emergency mental health services (Everly, 2000). Pastoral crisis intervention can lead to referral to other professionals or stand alone as a clinical service (and, as Patterson, Weil, \& Patel, 2010, point out, can even be integrated into more large-scale disaster responses along with other community resources).

\section{Support Services-The Middle of the Pyramid}

The middle of the service pyramid represents support functions that are not unique to persons experiencing behavioral health problems. The uniqueness of viewing these opportunities for ministry through the service pyramid is related to their specific application to behavioral health populations as part of a system of care. The system of care concept in behavioral health recognizes that people with mental health and substance abuse problems may require assistance meeting basic needs, such as housing and employment, in addition to clinical treatment. Just as it is difficult to concentrate and do well in school when a child is hungry, it is difficult to move toward wellness when one has a mental illness without a place to live or other basic needs met. Support services are natural extensions of ministry strengths for congregations and other religious groups. Examples of support services are reviewed below:

Housing. Persons with behavioral health issues may need assistance in accessing affordable, appropriate housing to remain in a supportive community. Many individuals lack the financial means to pay a deposit for rent or to purchase a home, and past housing failures often make it difficult to access community housing. Given the cyclical nature of many behavioral health disorders, they may have previously been unsuccessful at renting or owning and may lack references that landlords require. Faith-based organizations are capable of providing a variety of housing support options for persons with behavioral health problems such as outreach to homeless individuals offering assistance in accessing shelter (Reed, 1992); operating shelters for homeless individuals with a link to mental health and substance abuse service, or offering residential services (e.g., operating apartments or housing units, providing assistance in accessing housing, or assisting in the building of housing units through a program such as Habitat for Humanity). For children with behavioral health problems who cannot live in their natural homes, foster care may be provided by congregants until the child returns home, is adopted, or moves to a permanent placement. As with other support services, housing services do not include treatment, but are offered in conjunction with treatment.

One housing option that has enjoyed faith-based organizational support is the consumer-run recovery homes based on the Oxford House model (http://www.oxfordhouse.org/; see Jason \& Ferrari, 
2010 Jason, Ferrari, Davis, \& Olson, 2006; Jason, Olson \& Foli, 2008). The members of an Oxford House pay for rent and maintenance, set rules, and can vote members out for alcohol or drug use. Oxford Houses are self operated and only residents can decide who is accepted, who gets ejected, and how the home operates. Faith organizations interested in developing an Oxford House-type facility may 1) provide start-up funding such as rental deposit, 2) donate furnishings or cooking utensils, 3 ) assist with community acceptance and navigation of zoning laws, 4) assist in finding a willing landlord or co-signing the lease, or 5) refer individuals who might benefit from this living arrangement.

Independent Living Skills. Some individuals with behavioral health problems lack basic living skills. This may be particularly true for youth with serious emotional disorders transitioning to adulthood or for adults who have been institutionalized. Faith-based organizations, churches, synagogues, and mosques have members with expertise in a variety of areas, which give them exceptional credentials as life skill coaches in areas like selecting and preparing nutritional meals, balancing a check book, doing household maintenance, repairing an automobile, cleaning and keeping house, making wise consumer purchases, or accessing the internet to obtain information.

Financial. Individuals with a history of addictions or mental illness may have financial difficulties. Faithbased groups can help by providing direct financial support (e.g., food vouchers, housing subsidies, cash payments) or indirect support (e.g., credit counseling, providing information about savings, investments, insurance, and retirement planning). In situations where the individual is legally not competent to manage his or her finances, the religious organization or member may be appointed as conservator.

Persons with behavioral health issues may need assistance accessing or navigating government and private benefits such as Medicaid, Medicare, Social Security, food stamps, and private disability insurance. Individuals from faith organizations can be invaluable in helping a person navigate the complexity of federal, state, and local systems, eligibility requirements, points of access, and extensive paperwork. In some situations, individuals may need legal advocacy to ensure their rights are protected or they have access to resources for which they are entitled. Religious groups may provide advocacy directly or link the individual to community advocacy organizations.
Employment. Persons with mental health and substance abuse problems are at high risk of being unemployed. Faith-based organizations can play a valuable role in linking individuals to employment services such as vocational rehabilitation programs, job services, or specialized employment services offered through the behavioral health system. They may also provide assistance by teaching interview skills, career counseling, offering training in job searches, or helping in resume preparation. More advanced assistance may include job training or placement either within the faith organization or in a congregant's business. Finding affordable, appropriate child care during working hours may be a barrier to employment. Faith groups could assist in accessing day care or in accessing financial resources such as child care subsidies for low income working families. For individuals who cannot work, the faith group can offer volunteer opportunities to provide a sense of accomplishment and social interaction.

Education. In some cases, persons with behavioral health problems have difficulty accessing employment because they lack the necessary skills or education. Faith-based organizations may help the individual enroll in community educational programs such as GED programs, community colleges, trade schools, or universities. Faith communities may help link the person to educational opportunities that will meet his or her employment goals, ensure prerequisites are met, and applications are filled out appropriately. The organization may also have members who can serve as tutors or mentors. Another option is to arrange educational apprenticeships with businesses or organizations, in which the individual can gain job skills in a field of interest.

Transportation. Transportation is an area of special need for persons with behavioral health disorders, particularly in rural areas where little or no public transportation is available. Individuals could be taking medication or have a medical condition which makes driving unsafe, have had a license revoked or suspended for an alcohol or drug related offense, or may not have the financial means to afford transportation. Transportation difficulties create problems getting to treatment, obtaining and keeping employment, and meeting basic needs like grocery shopping. The faith-based organization can help the individual learn to access public transportation, provide driving instruction, coordinate charitable donations of automobiles or car parts such as 
tires, provide instruction in auto maintenance, or actually provide transportation.

Social/Recreational. Individuals with behavioral health issues often do not have the social and recreational opportunities enjoyed by others in our society because of the stigma associated with having problems, because the individual has been segregated (e.g., involvement in separate special education classes, being served in residential settings away from the community), because of a lack of opportunity to participate in community activities, or because the mental illness or substance abuse problem has interfered with the person's ability to socialize and recreate. The faith-based organization can help by creating opportunities for persons to join in social/recreational events sponsored by the church, synagogue, temple, mosque, or help the individual find appropriate social/recreational opportunities in the community (Rissmeyer, 1992). These activities may include classes or study groups, fellowship groups, organized recreational activities, religious camps, and community work projects. A pre-requisite for involving people with mental health and substance abuse problems in the social/recreational life of the church or faith group, is a climate of acceptance within the faith community. Breaking down stereotypes and the stigma associated with mental health and substance abuse is essential for real inclusion in social/recreational activities. A faith community may wish to provide educational opportunities for its members to better understand behavioral health issues to create a climate that is accepting and genuine for everyone.

Mentoring and Respite. A special form of social/recreational services is mentoring, such as a big brother or big sister program in which an older adolescent or adult helps provide social and recreational skills to a younger person or a recreational activity such as fishing, quilting, basketball, chess, or a social situation in which the individual can interact with others. Typically, this service has been used for children and adolescents with serious emotional disorders, but the approach may also be used for adults with behavioral health disorders.

A service closely related to mentoring is respite care. Respite care is designed to give caregivers a break from the daily assistance they provide to a loved one with a serious behavioral health problem. The respite worker is specially trained to respond appropriately to the behavioral health needs of the individual. Respite care may be provided in an indi- vidual's home or church, much like a baby sitter service, in a manner similar to mentoring, with the respite care worker taking the person out on a social or recreational activity, or in a residential setting such as a summer camp or a weekend retreat to provide extended rest for caregivers.

Care Management/Wraparound. Benefits assistance and advocacy are components of care management, a service to help individuals with behavioral health disorders coordinate service delivery, access benefits, and arrange for supports. One particular form of care management is a "wraparound approach" which attempts to wrap community services around an individual to meet their specific needs (e.g., Burchard, Bruns, \& Burchard, 2002; Burns \& Goldman, 1999). Generally, a wraparound coordinator works with the individual or family to convene a team of friends and professionals who develop individualized strategies to help the child or adult succeed where he or she lives, works and socializes (see Bruns, Suter, \& Leverentz-Brady, 2008). The resource coordinator should be trained in the wraparound process, group facilitation skills, safety planning, and strength-based planning. It is also helpful if the resource coordinator is knowledgeable about community resources, both professional and informal, and how to access them. Faith-based organizations are uniquely positioned to lead or participate in a wraparound process. Members of the faith organization can be trained in wraparound skills and become resource coordinators or members of faith organizations may participate as team members on wraparound teams as informal supports for the child/family or adult (VanDenBerg, 2003).

Education/Support Groups. Persons with behavioral health problems and their families can benefit through association with others who have had similar experiences in support groups. These groups combine mutual support with educational opportunities about promising intervention techniques or other relevant topics like self advocacy. Examples of support groups include Alcoholics Anonymous, Gamblers Anonymous, Narcotics Anonymous, and support groups for family members of children or adults with mental health disorders operated by organizations such as the Federation of Families for Children's Mental Health or the National Alliance for the Mentally Ill. Faith organizations can support these groups by providing a location for the group to meet, assisting with transportation, and offering snacks for meetings. 


\section{Information Services- \\ The Base of the Pyramid}

Faith organizations can provide a valuable service to an audience broader than a single congregation through dissemination of information through information and referral services and prevention approaches.

Information and Referral. Faith communities can help its members navigate the confusing maze of services and care systems. This is particularly relevant for persons with both mental and addiction problems who may require specialized services. (Substance Abuse and Mental Health Services Administration, n.d.). Referral, depending on individuals' circumstances, will fall along a continuum of fairly basic to very complex. A basic referral may simply be a one-time referral to a single agency. More complex situations may "call for multiple referral[s], repeated contacts with the inquirer, additional contacts with other members of the family, and a variety of referrals to relevant and appropriate agencies" (Levinson, 2002, p. 65). Although information may be available through phone books, brochures, or internet searches, these methods are often not sufficient to make credible referrals. The array of human services organizations and the services they provide may change dramatically over even short periods of time. To provide accurate and appropriate referrals, many organizations have found it advantageous to maintain information about community resources through low-tech card files or in sophisticated computerized software databases designed specifically for human services information and referrals. Organizing information for referrals should be considered on two dimensions: the depth of information about individual resources and the breadth of resources for which information resources are maintained.

It is important to consider how much information is needed to provide adequate referrals. Information about a service could include basic data such as agency name, type of service, and contact information or more complex information such as fees (e.g., acceptance of Medicaid), eligibility, accessibility, hours of operation, licensures, proximity to public transportation, key contacts, and translator or cultural competencies. The professional organization for information and referral services, the Alliance of Information and Referral Systems, has identified hundreds of commonly-used fields for maintaining information about individual resources.
Because persons with behavioral health issues may also need an array of other services and supports, faith communities may choose to maintain information about support services as well as behavioral health services. Faith communities should organize resource information for quick and easy retrieval. A taxonomy is an orderly classification of information that provides a common language for defining services. Without a common language it may be difficult for persons to quickly identify a needed resource because people may use different terminology to refer to the same service or the same terminology to refer to very different services. For example, one person may classify rental assistance resources under "renters" while another may think it should be classified under "housing." Many public and private information and referral organizations have adopted the AIRS/211 LA County taxonomy standard to define and organize resource information. This taxonomy organizes services into ten basic categories; these categories are further subdivided into five increasingly specific levels for over 6,300 types of services (InfoLine of Los Angeles, n.d.).

Faith communities with a desire to provide current, comprehensive information should consider the time-commitment and cost of maintaining its own resource information system. In instances in which multiple organizations within a community are maintaining information, it may make sense to consider partnering. With a little research, faith communities can quickly identify organizations within their area that maintain information about community resources. Indeed, information and referral services are found in nearly every community. For example, 2-1-1 call centers are available to over $80 \%$ of the nation's population (United Way of Ameri$\mathrm{ca} /$ Alliance of Information and Referral Systems, n.d.). A 2-1-1 center staffs a three-digit dialing code that has been reserved nationwide for community information and referral services.

Numerous collaborative opportunities exist for faith communities desiring to support resource identification and maintenance. Faith communities may be instrumental in creating systems in communities where they do not exist or choose to act as a contributor to a network of resource gatherers. This role may be especially helpful in instances where the faith community serves a population that traditionally is underserved (e.g., rural, ethnic/racial minorities, elderly). Faith communities may also provide financial support as part of an on-going commitment to 
community outreach and be an important conduit to referral information.

Prevention. Prevention can stop behavioral health problems before they occur or reduce problems before they become severe. Faith-based groups can employ a number of public information approaches through mediums such as radio or television public service announcements, billboard messages, and dissemination of informational brochures, public speaking engagements, or hosting workshops/conferences. Often these public information campaigns have a specific focus: examples include reducing alcohol use by pregnant women, reducing the stigma of mental illness so that individuals seek help early, or providing information about where to seek help.

Other prevention approaches may require specific interventions. One example of a promising prevention strategy is home visitation for high risk expecting mothers or parents of newborn children. This type of prevention has been shown to improve long-term outcomes for children, including their behavioral health (Olds, Eckenrode, Henderson, Kitzman, Powers, \& Cole, 1997; Olds, Henderson, \& Kitzman, 1994). Faith-based organizations may use parish nurses or other trained, experienced individuals to provide home visitation to at-risk mothers within the community. The faith organization may partner through an ecumenical effort with other faith or community groups, such as hospitals and public health organizations, to provide a comprehensive community-wide home visitation effort.

Another successful prevention strategy focuses on development of positive relationships for at-risk youth. Effective prevention efforts may focus on building strong relationships between the child and family through techniques like behavioral parent training (helping mothers and fathers gain skills in effective parenting), or family skills training (all family members attain and practice positive interaction and communication) (Kumpfer \& Alvarado, 2003). Other relationship-building efforts target interactions with peers (Mulvey, Arthur \& Repucci, 1993) or with other adults in the community (Grossman \& Tierney, 1998). Faith-based organizations may also establish activities that bring together youth in efforts to establish healthy peer and adult relationships.

Suicide is a public health problem that is preventable (U.S. Department of Health and Human Services, 1999a). There are a number of activities that can lessen the stigma associated with getting help for treatable illnesses like depression or bipolar disease and provide education about risk factors and warning signs of suicide (U.S. Department of Health and Human Services, 1999b, 2001). Faith communities can, for example, pair depression screening with blood pressure checks commonly held as part of parish nurse or health activities. Faith community members who volunteer to reach out to the elderly, lead the youth, or visit the sick can be educated to look for signs of depression or signs of suicide. Faith communities are uniquely positioned to serve as a connector between underserved, difficult to access populations and research efforts that are designed to generate new information about suicide and mental illness. Religious organizations may choose to adopt other promising efforts that research has already shown to be successful in preventing substance abuse and behavioral health disorders (Substance Abuse and Mental Health Services Administration Model Programs, 2008; National Registry of Evidence Based Programs and Practices, n.d.).

\section{Conclusion}

Faith communities have an important role to play in addressing behavioral health needs and connecting persons in need with the services that will assist them. For many congregations, this is part of their mission and tradition; for others, it represents part of their involvement in the community. The framework described in this article identifies possible points of connection between faith organizations and behavioral health care systems. Much of the framework is a translation of professional jargon to create a bridge of understanding about how behavioral health can leverage faith organization assets and how faith organizations can support individual members and their communities. Behavioral health systems provide expertise to treat problems while faith organizations provide communities that promote healing and recovery. In partnership they offer a path to wellness for people who have mental health, substance abuse or addiction problems.

\section{REFERENCES}

Ali, O. M., Milstein, G., \& Marzuk, P. M. (2005). The imam's role in meeting the counseling needs of Muslim communities in the United States. Psychiatric Services, 56, 202-205.

Allard, S. W., Tolman, R. M., \& Rosen, D. (2003). Proximity to service providers and service utilization among welfare recipients: The interaction of place and race. Journal of Policy Analysis and Management, 22, 599-613. 
Atkins, D. C., \& Christensen, A. (2001). Is professional training worth the bother? A review of the impact of psychological training on client outcome. Australian Psychologist, 36 (2), 1-9.

Bergman, R. L. (1974). Paraprofessionals in Indian mental health programs. Psychiatric Annals, 4, 76-84.

Bissonette, R. (1977a). The bartender as a mental health service gatekeeper: A role analysis. Community Mental Health Journal, 13, 92-99.

Bissoneete, R. (1977b). The mental health gatekeeper role: A paradigm for conceptual pretest. International Journal of Social Psychiatry, 23, 31-34.

Bos, A. D. (1993). A practical guide to community ministry. Louisville, KY: Westminster/John Knox Press.

Brat, P. (2001). Aging, mental health and the faith community. Journal of Religious Gerontology, 13(2), 45-54.

Bronfenbrenner, U. (1979). The ecology of human development: Experiments by nature and design. Cambridge, MA: Harvard University Press.

Brown, W. F. (1974) Effectiveness of paraprofessionals: The evidence. Personnel \& Guidance Journal, 53, 257-263.

Bruns, E. J., Suter, J. C., \& Leverentz-Brady, K. (2008). Is it wraparound yet? Setting quality standards for implementation of the wraparound process. Journal of Behavioral Health Services \& Research, 35, 240-252.

Burchard, J. D., Bruns, E. J., \& Burchard, S. N. (2002). The Wraparound process. In B. J. Burns, K. Hoagwood, \& M. English, Community-based interventions for youth (69-90). New York: Oxford University Press.

Burns, B. J., \& S. K. Goldman (Eds.) (1999). Promising practices in wraparound for children with serious emotional disturbance and their families. Systems of Care: Promising Practices in Children's Mental Health, Volume 4. Washington, D.C.: Center for Effective Collaboration and Practice, American Institute for Research.

Caldwell, C. H., Greene, A. D., \& Billingsley, A. (1994). Family support programs in Black churches: A new look at old functions. In S. L. Kagan \& B. Weissbourd (Eds.), Putting families first: America's family support movement and the challenge of change (pp. 137-160). San Francisco, CA: Jossey-Bass/Pfeiffer.

Canning, S. S. (2005). Psychological resources in faith-based community settings: Applications, adaptations, and innovations. In M. R. McMinn \& A. W. Dominguez (Eds.), Psychology and the church (pp. 137-143). Hauppauge, NY: Nova Science.

Chamberlain, P. (2002). Community treatment for youth: Evidence-based interventions for severe emotional and behavioral disorders. In B. J. B. K. Hoagwood (Ed.), Treatment foster care. (pp. 117-138). New York: Oxford University Press.

Chamberlain, P., \& Moore, K. (1998). A clinical model for parenting juvenile offenders: A comparison of group care versus family care. Clinical Child Psychology \& Psychiatry, 3, 375-386.

Christens, B., Jones, D. L., \& Speer, P. W. (2008). Power, conflict, and spirituality: A qualitative study of faith-based community organizing. Forum: Qualitative Social Research, 9(1), Art. 21. Retrieved from http://www.qualitativeresearch.net/index.php/fqs/article/view/330.
Christensen, A., \& Jacobson, N. S. (1994). Who (or what) can do psychotherapy: The status and challenge of nonprofessional therapies. Psychological Science, 5, 8-14.

Clemens, N. A. (2005). The faith community and mental health care. Psychiatric Services, 56, 133.

Collins, A. H. (1973). Natural delivery systems: Accessible sources of power for mental health. American Journal of Orthopsychiatry, 43, 46-52.

Cowen, E. L. (1982). Help is where you find it: Four informal helping groups. American Psychologist, 37, 385-395.

D’Augelli, A. R., \& Vallance, T. R. (1981). The helping community: Promoting mental health in rural areas through informal helping. Journal of Rural Community Psychology, 2, 3-16.

Dossett, E., Fuentes, S., Klap, R., \& Wells, K. (2005). Brief reports: Obstacles and opportunities in providing mental health services through a faith-based network in Los Angeles. Psychiatric Services, 56, 206-208.

Drayton-Brooks, S., \& White, N. (2004) Health promoting behaviors among African American women with faith-based support. ABNF Journal 15(5), 84-90.

Dudley, C. S., \& Roozen, D. A. (2001). Faith communities today: A report on religion in the United States today. CT: Hartford Seminary, Institute for Religion Research.

Eng, E., Hatch, J., \& Callan, A. C. (1985). Institutionalizing social support through the church and into the community. Health, Education, \& Behavior, 12, 81-92.

Everly, G. S. J. (2000). The role of pastoral crisis intervention in disasters, terrorism, violence, and other community crises. International Journal of Emergency Mental Health, 2(3), 139-142.

Foskett, J. (2001). Can pastoral counseling recover its roots in madness? British Journal of Guidance \& Counseling, 29, 403-413.

Gordon, J. E. (1974). The development of paraprofessionals in employment work. Personnel and Guidance Journal, 53, 289-293.

Grossman, J. B., \& Tierney, J. P., (1998). Does mentoring work? An impact study of the Big Brothers Big Sisters program. Evaluation Review, 22, 403-426.

Gunderson, G. (1997). Deeply woven roots. Minneapolis, MN: Augsburg Fortress Publishers.

Hatch, J., \& Derthick, S. (1992). Empowering Black churches for health promotion. Health Values: The Journal of Health Behavior, Education \& Promotion, 16(5), 3-9.

Hunter, A., \& Riger, S. (1986). The meaning of community in community mental health. Journal of Community Psychology, 14, 55-71.

InfoLine of Los Angeles (n.d.) Taxonomy of human services: a conceptual framework with standardized terminology and definitions for the field. Retrieved September 30, 2003 from http://www.infoline-la.org/f-prod.htm

Jason, L. A., \& Ferrari, J. R. (Eds.). (2010). Recovery from addictions in communal living settings: The Oxford House model. New York: Routledge. 
Jason, L. A., Olson, B. D., \& Foli, K. J. (2008). Rescued lives: The Oxford House approach to substance abuse. New York: Routledge.

Jason, L. A., Ferrari, J. R., Davis, M. I., \& Olson, B. D. (2006). Creating communities for addiction recovery: The Oxford House model. New York: Haworth.

Johnsson, K. O., \& Berglund, M. (2003). Education of key personnel in student pubs leads to a decrease in alcohol consumption among the patrons: A randomized controlled trial. Addiction, 98, 627-633.

Kelley, P., \& Kelley, V. R. (1985). Supporting natural helpers: A cross-cultural study. Social Casework, 66, 358-366.

Kloos, B., Horneffer, K., \& Moore, T. (1995). Before the beginning: Religious leaders' perceptions of the possibility for mutually beneficial collaboration with psychologists. Journal of Community Psychology, 23, 275-291.

Kramer, F. D. (2010). The role for public funding of faith-based organizations delivering behavioral health services: Guideposts for monitoring and evaluation. American Journal of Community Psychology, 46, 342-360.

Kress, J. S., \& Elias, M. J. (2000). Infusing community psychology and religion: Themes from an action-research project in Jewish identity development. Journal of Community Psychology, 28, 187-198.

Kretzmann, J. P., \& McKnight, J. L. (1993). Building communities from the inside out: A path toward finding and mobilizing community assets. Chicago, IL: ACTA Publications.

Kumpfer, K. L., \& Alvarado, R. (2003). Family-strengthening approaches for the prevention of youth problem behaviors. American Psychologist, 58, 457-465.

Levinson, R. W. (2002). New routes to human services. Springer Publishing Company: New York.

Maton, K. I., \& Pargament, K. I. (1987). The roles of religion in prevention and promotion. Prevention in Human Services, 5, 161-205.

McKim, B. J., \& Weissberg, R. P. (1981). Bartenders as informal, interpersonal help-agents. American Journal of Community Psychology, 9, 715-729.

McRay, B. W. (2001). What Evangelical pastors want to know about psychology. Journal of Psychology and Theology, 29, 99-105.

Miskelly, S. (1995). A Parish Nursing model: applying the community health nursing process in a church community. Journal of Community Health Nursing, 12(1), 1-14.

Morton, B., \& Joseph, Z. (1971). The prevention of family violence: Dilemmas of community intervention. Journal of Marriage and the Family, 33, 677-682.

Mulvey, E. P., Arthur, M. W., \& Reppucci, N. D. (1993). The prevention and treatment of juvenile delinquency: A review of the research. Clinical Psychology Review, 13, 133-167.

National Council for Community Behavioral Healthcare. (n.d.). Building healthy communities. Rockville, MD: Author.

National Institute of Mental Health. (2003). The numbers count: Mental disorders in America (NIMH Publication No. 01-4584). Rockville, MD: Author.
National Registry of Evidence-Based Programs and Practices (n.d.). Available online at http://nrepp.samhsa.gov/.

New Freedom Commission on Mental Health (2003). Achieving the promise: Transforming mental health care in America. Final Report. Rockville, MD: US Department of Health \& Human Services. Available online at www.mentalhealthcommission.gov.

Olds, D., Eckenrode, J., Henderson, C. J., Kitzman, H., Powers, J., \& Cole, R. (1997). Long-term effects of home visitation on maternal life course and child abuse and neglect: Fifteen-year follow-up of a randomized trial. Journal of the American Medical Association, 278, 637-643.

Olds, D., Henderson, C. J., \& Kitzman, H. (1994). Does prenatal and infancy nurse home visitation have enduring effects on qualities of prenatal caregiving and child health at 25 and 50 months of life? Pediatrics, 93, 89-98

Patterson, O., Weil, F., \& Patel, K. (2010). The role of community in disaster response: Conceptual models. Population Research \& Policy Review, 29, 127-141

Reed, D. A. (1992). Adaptation: The key to community psychiatric practice in the rural setting. Community Mental Health Journal, 28, 141-150.

Richards, P. S., \& Bergin, A. E. (Eds.). (2000). Handbook of psychotherapy and religious diversity. Washington, DC: American Psychological Association.

Rissmeyer, D. J. (1992). The church social club: Serving the longterm mentally ill through ecumenical ministry. Journal of Psychology and Christianity, 11(1), 69-75.

Roach, A. M., \& Resnick, H. (1981). Training bartenders as helpers on a college campus. Personnel and Guidance Journal, 60, 119-121.

Small, M. A. (2001). Public service and outreach to faith-based organizations. Journal of Higher Education, 6, 57-65.

Small, M. (2002). Achieving community justice through faithbased initiatives. Behavioral Sciences of the Law, 20, 411-421.

Speer, P. W., Peterson, N. A., Zippay, A., \& Christens, B. D. (2010). Participation in congregation-based community organizing: Mixed-method study of civic engagement. In M. RobertsDegennaro \& S. J. Fogel (Eds.), Using evidence to inform practice for community and organizational change (pp. 200-217). Chicago: Lyceum Books.

Spriggs, J. D., \& Sloter, E. (2003). Counselor-clergy collaboration in a church-based counseling ministry. Journal of Psychology and Christianity, 22, 323-326.

Stroul, B (Ed.). (1996). Creating systems of care in a changing society. Baltimore, MD: Paul H. Brooks Publishing Co.

Substance Abuse and Mental Health Services Administration. (n.d.). Strategies for developing treatment programs for people with co-occurring substance abuse and mental disorders (SAMHSA Publication No. 3782). Rockville, MD: Author.

Substance Abuse and Mental Health Services Administration. (2003). Results from the 2002 National Survey on Drug Use and Health: National Findings (NHSDA Series H-22, DHHS Publication No. SMA 03-3836). Rockville, MD: Author. 
Substance Abuse and Mental Health Services Administration Model Programs. (2008). Effective substance abuse and mental health programs for every community. Available online at http://www.modelprograms.samhsa.gov/model.htm.

Tan, S. Y. (1991). Lay counseling: Equipping Christians for a helping ministry. Grand Rapids, MI: Zondervan.

Tan, S. Y. (2002). Lay helping: The whole church in soul care ministry. In T. Clinton \& G. Ohlschlager ( Eds.), Competent Christian counseling, Vol. 1 ( pp.424-436, 759-762). Colorado Springs, CO: WaterBrook Press.

Taylor, R. J. (1986). Religious participation among elderly Blacks. Gerontologist, 26, 630-636.

Taylor, R. J., \& Chatters, L. M. (1986a). Church-based informal support among elderly Blacks. Gerontologist, 26, 637-642.

Taylor, R. J., \& Chatters, L. M. (1986b). Patterns of informal support to elderly Black adults: Family, friends, and church members. Social Work, 31, 432-438.

Thompson, J. J. (1993). Women, welfare, and college: The impact of higher education on economic well-being. Affilia: Journal of Women and Social Work, 8, 425-441.

U.S. Department of Health and Human Services. (1999a). Mental health: A report of the Surgeon General. Rockville, MD: Author. Available online at http://mentalhealth.samhsa.gov/features/surgeongeneralreport /home.asp\#topper.

U.S. Department of Health and Human Services. (1999b). The Surgeon General's Call to Action to prevent suicide. Rockville, MD: Author. Available online at http://download.ncadi.samhsa.gov/ken/pdf/suicideprevention/ calltoaction.pdf

U.S. Department of Health and Human Services. (2001). National strategy for suicide prevention: Goals and objectives for action. Rockville, MD: Author. Available online at http://download.ncadi.samhsa.gov/ken/pdf/SMA013517/SMA01-3517.pdf

United Way of America/Alliance of Information and Referral Systems. (n.d.). Nationwide status. Retrieved December 13, 2010, from http://.211us.org/status.html.

VanDenBerg, J. (2003). Community values: Wraparound/system of care. Available online at www.vroonvdb.com/about_communityvalues.html.

Voss, S. L. (1996). The church as an agent in rural mental health. Journal of Psychology \& Theology, 24, 114-123.
Wang, P. S., Berglund, P. A., \& Kessler, R. C. (2003). Patterns and correlates of contacting clergy for mental disorders in the United States. Health Services Research, 38, 647-673.

Zarle, T. H., Hartsough, D. M., \& Ottinger, D. R. (1974). Tornado recovery: The development of a professional-paraprofessional response to a disaster. Journal of Community Psychology, 2, 311-320.

\section{Authors}

DeKRAAI, MARK. Address: University of Nebraska Public Policy Center 215 Centennial Mall South, Suite 401 PO Box 880228 Lincoln, NE 68588-0228. Email: mdekraai@nebraska.edu. Title: Senior Research Director, University of Nebraska Public Policy Center. Degrees: J.D., Ph.D. Areas of Specialization: Child and family systems of care, mental health and substance abuse services, and other health and human services. He is interested in how public engagement processes and evaluation results inform public policy.

BULLING, DENISE. Address: University of Nebraska Public Policy Center 215 Centennial Mall South, Suite 401 PO Box 880228 Lincoln, NE 68588-0228. Email: dbulling@nebraska.edu. Title: Senior Research Director, University of Nebraska Public Policy Center. Degree: Ph.D. Areas of Specialization: Disaster/emergency behavioral health and threat/risk assessment and management. She enjoys applied research that creates shared understanding among practitioners, policy makers and academicians via strategic planning, public engagement and program evaluation.

SHANK, NANCY. Address: University of Nebraska Public Policy Center 215 Centennial Mall South, Suite 401 PO Box 880228 Lincoln, NE 68588-0228. Email: nshank@nebraska.edu. Title: Associate Director, University of Nebraska Public Policy Center. Degree: Ph.D. Areas of Specialization: Technology adoption, interoperability for information sharing between organizations, information and referral, economic and community development, organizational systems and behavior, and human services systems.

TOMKINS, ALAN. Address: University of Nebraska Public Policy Center 215 Centennial Mall South, Suite 401 PO Box 880228 Lincoln, NE 68588-0228. Email: atomkins@nebraska.edu. Title: Associate Director, University of Nebraska Public Policy Center. Degrees: J.D., Ph.D. Areas of Specialization: Public participation and its implications for democracy in policymaking, public trust and confidence in government (especially the courts), the interplay between policies and behaviors, behavioral health systems of care and related practices and policies, program evaluation, and examining issues of justice, fairness and the impact of scientific information in the water resources context. 
Copyright of Journal of Psychology \& Theology is the property of BIOLA University and its content may not be copied or emailed to multiple sites or posted to a listserv without the copyright holder's express written permission. However, users may print, download, or email articles for individual use. 